\title{
Usability Evaluation of Anthropomorphic Prosthetic Hand Based on ISO 9241-11
}

\author{
Novie Susanto ${ }^{1, *}$, Wiwik Budiawan ${ }^{1}$, Rifky Ismail $^{2}$, Mochammad.Ariyanto ${ }^{2}$ and \\ Ahmad Sahal ${ }^{1}$ \\ ${ }^{1}$ Industrial Engineering Department, Faculty of Engineering, Diponegoro University, Semarang \\ ${ }^{2}$ Centre for Biomechanics, Biomaterials, Biomechatronics and Biosignal Processing (CBIOM3S), \\ Central Laboratory Building, $5^{\text {th }}$ Floor, Diponegoro University, Semarang
}

\begin{abstract}
This paper aims at evaluating an anthropomorphic prosthetic hand based on usability concept. It can be controlled for pre-defined five motions. The assessment is conducted by design approach. Users are given the task according to the rules of hand benchmarking in Southampton Hand Assessment Procedure (SHAP) by using Anthropomorphic Prosthetic Hand to perform daily activities. The quantitative data is obtained by a test that based on the criteria of learnability, memorability, satisfaction, efficiency and errors. The qualitative data is obtained by giving USE (Usefulness, Satisfaction and Ease of Use) questionnaires. The recommendation design is prepared by using Quality Function Deployment (QFD) method to combine suggestions from respondents and product developers. Assessment by USE questionnaires shows that the usability level of Anthropomorphic Prosthetic Hand on the aspect of usefulness is $68.3 \%$ and $63.8 \%$; satisfaction is $59.5 \%$ and $55.6 \%$. The improvement recommendations based on the result of (QFD) are Variant material to connect to the arm, System to connect to arm, Dimension of connecting to arm, Connection information to the arm, and Instructions for the exercise stage. So that improvement is done in accordance with ISO 9241-11: 1998.
\end{abstract}

\section{Introduction}

The success of industry is determined by two things. First, success in designing and developing products that suit the consumer's wishes. Second, the speed of the industry is in adapting/responding to changes in consumer desires [1]. Various product innovations are developed as a manufacturer's step to get customers from various sectors. One sector that can not be separated from the creation of various innovative products is the health field. This field is considered quite potential as one of the media product development in accordance with one's personal needs.

Aids in the health field can be said to be an instrument, apparatus, machine, and implant containing no medication. The tools are used to prevent, diagnose, cure and alleviate illness, treat the sick, restore health to humans, and structure and improve body function [2].

\footnotetext{
*Corresponding author: novie.susanto@,ft.undip.ac.id
} 
One type of tool that is often used is a tool of human motion. This tool is commonly used for patients who have physical deficiencies due to various things that have occurred such as accidents, diseases, and heredity [3]. In general, the main function of the tool is to help and ease the patient's complaints [4]. Manufacturers are required to create a tool that suits the needs of the patient. The development of research on hand tool products for disabled persons in Indonesia is not much. This is due to the high cost of purchasing a variety of sensors used to make tools to have the same function with human hands [5]. Therefore, this tool is designed to help develop research on tools for hand disability patients although in the manufacture of the product it is only equipped with some features of hand movement.

Anthropomorphic Prosthetic Hand (Fig. 1) is one of the motion aids developed by Diponegoro University Mechanical Engineering which is specially designed for disabled persons [5]. It is designed based on a custom dimension of Indonesian. It controls some predefined movements as designed by the product developer. Anthropomorphic Prosthetic Hand uses a drive motor with a linear type Actuonic PQ-12 acuator mounted inside an artificial hand component. The materials used are PLA (Polylactid Acid) with brown color and printed using 3D printer. Microcontroller or brain control on Anthropormophic Prosthetic Hand is Arduino nano which is one type of microcontroller developer board with a small size and complete function. As an indicator of the current movement, Anthropormophic Prosthetic Hand using RGB LED lights. Each color emitted to inform what movement is active [5].
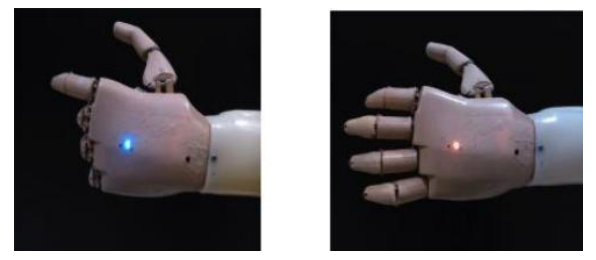

Fig. 1 Anthropomorphic Prosthetic Hand

This tool is designed based on the human dimension of Indonesia. The designer can control this tool for some predetermined movement. Anthropormophic Prosthetic Hand uses a motor with a linear type Actuonic PQ-12 actuator mounted inside an artificial hand component. The material used is PLA (Polylactid Acid) with brown color and printed with 3D printer. The microcontroller used in Anthropormophic Prosthetic Hand is Arduino nano. Arduino nano is one type of microcontroller developer board that has a small size and complete. As an indicator of movement, this tool use RGB LED light. The color of the emitted lamp informs what movement is active [5]. The majority of people with disabilities in Indonesia use artificial hands and feet that are passive [6]. Passive aids cannot perform the main function of patients with disabilities. America, China, and Britain have developed an active artificial hand. The Aids can move automatically according to what the patient wants. The active tool can move with electromyograph (EMG) sensor or electroencephalograph (EEG) sensor. EMG and EEG are sensors used to capture the input signal and muscle contraction of the patient's arm.

Currently, the increasing demand for medical equipment has not been followed by the development of domestic industry. This causes $90 \%$ of health equipment circulating in Indonesia is imported products [7]. The price provided by the manufacturer is also high because of the active functionality of the disability tool. Manufacturers must install several sensors used to capture the input signal from the patient's muscle contraction. Therefore, the people of Indonesia prefer to use passive motion tools (cheaper).

Development of Anthropomorphic Prosthetic Hand is expected to suit the needs of users (dimensions and prices). In support of the creation of products that suit the needs of users, testing and evaluation needs of the product. One of the evaluations that can be done is the usability of the product [8]. This evaluation is needed to assess how far the product is made to 
meet the needs of consumers so that later consumers will feel satisfied when using the product. Based on these conditions, it can be formulated problem about evaluation Usability use of Anthropomorphic Prosthetic Hand. Evaluation is needed to measure how easily the product can be understood and used by the patient. The measured Usability Criteria are Learnability, Memorability, Errors Efficiency and Satisfaction. The data was collected by experiment according to the Southampton Hand Assessment Procedure (SHAP) handling procedure and completed with USE (Usefulness, Satisfaction and Ease of Use) questionnaire.

\section{Methods}

The purposes of this research are to identify the factors that influence the level of ease of use of Anthropomorphic Prosthetic Hand product, to measure the usability level of Anthropomorphic Prosthetic Hand product on handicapped patient with USE (Usefulness, Satisfaction and Ease of Use) questionnaire, and to propose improvement on Anthropomorphic Prosthetic Hand products use QFD (Quality Function Deployment) method. To answer the purpose of research, there are several stages of research done. Stages of research done are Research Design, Identify Variables, Experiment, Result Analysis, and Product Improvement [10].

\subsection{Research Design}

In this study, testing the tool to the handicapped persons respondents does the assessment of product development performance. Respondents will be given information about the research step. Taking video as a tool for measuring the time when respondents do the task does research. The data of the research were collected for analysis of usability level. The analysis results are then used as the basis for the input of the QFD method. Research data used for this research is quantitative and qualitative data. For quantitative measurements this study refers to Jacob Nielsen's theory of measuring the usability of a product or system. Usability parameters are used because there are appropriate criteria for new products or systems [9]. There are 5 usability criteria: learnability, efficiency, memorability, errors and satisfaction. Qualitative data collection was collected by questionnaire. There are several types of questionnaires that can be used to measure the level of ease of use of products or systems, namely USE (Usefulness, Satisfaction and Ease of use), CSUQ (Computer System Usability Questionnaires) and PUTQ (Purdue Usability Testing Questionnaire). Of the several types of questionnaires are mostly used to measure the product or digital system with consideration of human computer interaction system. Thus, the questionnaire used in this study is USE. USE can be used for evaluation of usability of non-digital products.

\subsection{Identify Variables}

There are 2 variables in this research that is Independent Variable and Dependent Variable. The independent variable in this study is the size and features of Anthropomorphic Prosthetic Hand products. The dependent variable in this study is the level of Learnability, Efficiency, Memorability, Errors and Satisfactions. It also complies with the standard Ergonomic requirements for office work with visual display terminals (ISO 9241-11:1998) [14]: Learnability (The level of ease of learning of Anthropomorphic Prosthetic Hand products is measured by interviewing the respondents); Efficiency (The level of efficiency is measured by measuring the respondent's time doing the task); Memorability (The level of Memorability is measured by repeating the tests performed with the same task without instruction); Errors 
(The level of errors is measured by how the respondent performs the assigned task); and, Satisfaction (The level of user satisfaction Anthropomorphic Prosthetic Hand is measured by interviews shortly after the responder experiments.)

\subsection{Experiment}

Anthropomorphic Prosthetic Hand products were then tested on handicapped persons to measure these factors. Tests performed are the standard daily activities defined by the SHAP (Southampton Hand Assessment Procedure). Then the experiment is measured based on the criteria of Learnability, Efficiency, Memorability, Errors and Satisfactions. Based on the five functions (Tripod, Active Index, Precision Closed, Power grip, Hook) that exist in the Anthropomorphic Prosthetic Hand, the activities in the SHAP are capable of: Taking coin (Active index); Moving objects Cylindrical light (Power grip); Moving the tray / tray (Precision closed); Opening the door with the handle (Hook); Pour water from a carafe into a glass (Tripod); Cut with a knife (Power grip); and Opening / closing the zipper (Active index).

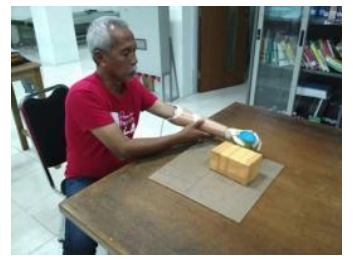

Fig. 2 Activity Moving Objects

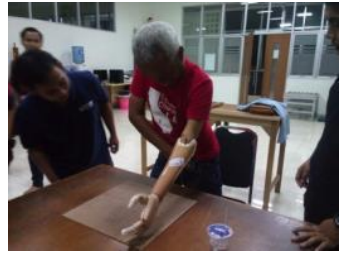

Fig. 3 Activity Take a Coin

\subsection{Data Analysis}

In this section the data collected from the respondents is analysed more deeply. The results of data recapitulation were analysed to the measured criteria for later design of proposed improvement on Anthropomorphic Prosthetic Hand products.

\subsection{Product Improvement}

There are several methods used as the basis for the preparation of product evaluation. Among them are: QFD (Quality Function Deployment), QUAD (Quality and Usability Assured Design), and UCD (User Cantered Design). For design improvement, QFD (Quality Function Deployment) method is used in this research. The QFD method is chosen because it considers the respondent's voice as a consumer of the Anthropomorphic Prosthetic Hand product [10]. The stages of QFD are:

1. Voice of Customer: In the early stages is the interview after the product is tested to the respondent. Respondents were given a USE questionnaire to obtain qualitative data. Questionnaire results are seen aspects that have a low scale (scale below the middle value) of the assessment respondents. This low-scale aspect is an unmet consumer need when using Anthropomorphic Prosthetic Hand

2. House of Quality: House of Quality is a useful matrix for transforming consumer needs into a technical system for a product. The process is to set priorities for each of the characteristics and target development of the product [11][12][13].

3. Analysis and interpretation: The HoQ matrix is compiled using template matrix (QFD Method). The HoQ matrix is used as the design benchmark. Then, the HoQ Matrix 
Results are analyzed and interpreted to obtain product improvement recommendations.

Product improvement recommendations are generated according to customer needs.

\section{Result and Discussion}

In this study the respondents who successfully collected a number of two people. Two respondents have similar characteristics. Characteristics include: Disability on the left hand with elbow borders/ Disability limit. The number of persons with disabilities with similar characteristics is not much. This should be answered with the flexibility of Anthropomorphic Prosthetic Hand products. Furthermore, Anthropomorphic Prosthetic Hand is used on both respondents. Respondents then run daily activities determined by SHAP. When running SHAP activities, respondents assessed the achievement of the time. Time measurements other than using stopwatch, also re-verified with video recording. Some of the daily activities defined by SHAP include: Open the Door; Take a Coin; Moving Objects; and Opening Zippers. During the five experiments, the average time required to perform the activity decreased (both respondents). Table time decrease performance can be seen in Table 1.

Table 1. Time Decrease Performance (Seconds)

\begin{tabular}{|r|c|c|c|c|}
\hline No. & Open The Door & Moving Objects & Take a Coin & Opening The Ziper \\
\hline 1 & 12.06 & 3.89 & 39.05 & 26.98 \\
\hline 2 & 9.35 & 3.67 & 50.47 & 19.59 \\
\hline 3 & 2.02 & 3.19 & 47.11 & 10.59 \\
\hline 4 & 2.29 & 3.07 & 33.75 & 10.01 \\
\hline 5 & 3.16 & 3.05 & 27.5 & 2.35 \\
\hline
\end{tabular}

After the experiment, then the respondents fill out the questionnaire. The questionnaire is used to answer some aspects of the product. Aspects of these products include: usefulness, ease of use, learnability, and satisfaction. There are 30 questions in the questionnaire. The assessment results of both respondents, Anthropomorphic Prosthetic Hand products overall status of the four aspects is "GOOD" (Total usability level Respondent 1: $71.8 \%$ and Respondent 2: $73.2 \%$ ). Based on the recapitulation of four aspects (usefulness, Ease of use, Learnability, and Satisfaction), there are two aspects that have an average of less than $70 \%$. Both aspects are Usefulness and Satisfaction. Both aspects are then verified to both respondents. The interview results found some obstacles in the aspects of Usefulness and Satisfaction.

1. Early use of Anthropomorphic Prosthetic Hand product cannot be directly used. Users should familiarize themselves when using the product.

2. At the time of connection need a flexible hook mechanism because the dimensions of the human body variant.

Furthermore the results of such data are used as the basis for product improvement (QFD). To determine priorities for improvement of technical characteristics, each technical characteristic is ranked based on the value of the contribution of technical characteristics. Considering the fulfilment of attribute needs and achievement targets also does the priority determination of the development of technical characteristics. Based on the results of the ranking and the fulfilment of the target technical characteristics, then selected 5 attributes that have not met the target and can represent all the attributes of customer needs: (1) Variant material to connect to the arm; (2) System to connect to the arm; (3) Dimension of connecting to arm; (4) Connection information to the arm; and, (5) Instructions for the exercise stage. Of the 5 attributes selected, then the discussion of concepts. The concept aims to focus on improvements that will be done by the developer. By conceptualizing, the improvements made will have more variation in the improvement. The design of the concept will select all 
the attributes found in the previous experiment. However, alternative concepts will be discussed in subsequent research.

\section{Conclusion}

Excellent status on Anthropomorphic Prosthetic Hand products must be achieved so that customers feel satisfied. The downside of the Anthropomorphic Prosthetic Hand product is found in the aspects of usefulness and satisfaction. Then the discovery of these two aspects is used in product improvement. Future product improvements will focus on five attributes. The five attributes are: Variant material to connect to the arm, System to connect to arm, Dimension of connecting to arm, Connection information to the arm, and Instructions for the exercise stage. These improvements are made to obtain the standard Ergonomic requirements for office work with visual display terminals (ISO 9241-11: 1998).

\section{References}

1. Flores, J., Gonçalves-Coelho, A., Mourão, A., Cavique, M. Theory of practices as a means to uncover the customer needs. 9th International Conference on Axiomatic Design - ICAD 2015. Elsevier Publisher (2015)

2. Clarckson, Douglas M, Medical Device Guidebook: A browser information resource for medical device users. Elsevier Publisher (2017)

3. Lazar, J.,Feng, HJ., Hochheiser, H. Working with research participants with disabilities : Research Methods in Human Computer Interaction (Second Edition). Elsevier Publisher (2017)

4. Wang, N., Lao, K., Zhang, X. Design and Myoelectric Control of an Anthropomorphic Prosthetic Hand. Journal of Bionic Engineering. 14, 47. Elsevier Publisher (2017)

5. Primarezky, E. Development of 5 DOF Myoelectric Prosthetic Hand in Hand Patients With Disability Semarang. Department of Mechanical Engineering Diponegoro University (2017)

6. Riskesdas. Data riskesdas. Access: March 2017, Ministry of Health: www.depkes.go.id/resources/download/general/Hasil\%20Riskesdas\%202013. Pdf (2013)

7. Kemenkes. Health Profile. Access March 2017, Ministry of Health: www.depkes.go.id/resources/download/.../profil-kesehatan-indonesia-2013.pdf (2013)

8. Chisnel, D. Hand Book of Usability Testing. Indianapolish. Wiley publisher (2008)

9. Xiangwei, L.,Yun, B.,Yuhui, Q. Measuring Usability: Use HMM Emotion Method and Parameter Optimize. Springer Publisher (2006)

10. Revelle, Jack B. Quality Essentials: A Reference Guide from A to Z. ASQ Publisher. (2004)

11. Gazpersz, V. Analysis Methods to Improve Quality. Gramedia Indonesia. (2001)

12. Jonnasen, David H. Problem-Based Learning: Encyclopedia of the Sciences of Learning. Springer Publisher (2012)

13. Cohen, L. Quality Function Deployment: How to Make QFD Work for You. AddisonWesley, Inc. (1995) 